\title{
ENVIRONMENTAL NOISE AND AIR POLLUTION MONITORING IN THE ATHENS RING ROAD ('ATTIKI ODOS') AN IMPORTANT PARAMETER FOR A SUSTAINABLE URBAN DEVELOPMENT
}

\author{
K. VOGIATZIS \\ Faculty of Civil Engineering, Transportation Department, University of Thessaly, Greece.
}

\section{ABSTRACT}

Attica Tollway (Attiki Odos), a modern motorway extending along $65 \mathrm{~km}$, constitutes the ring road of the greater metropolitan area of Athens and the main road network of the Attica Prefecture with over 4.5 million inhabitants. Attiki Odos from the first year of its operation in early 2001, in close collaboration with the University of Thessaly-Faculty of Civil Engineering (Laboratory of Transportation Environmental Acoustics), ensures a full environmental noise and air pollutants monitoring program based on eight fixed stations resulted in the implementation of an extensive Environmental Action Plan in order to ensure the system's sustainability. This article presents the main technical and operation characteristics of this extensive monitoring as well as the results and conclusions of the last 18-month period. A full assessment of the relevant environmental impact both on the acoustic and atmospheric environment is analyzed in this article along with comparative analysis for all monitoring locations including traffic data. This monitoring program consists one of the main parameters for an urban sustainable development of road transport in Athens Mega Region.

Keywords: Air pollution, environmental monitoring, environmental noise, road traffic noise, sustainable development, transportation noise, urban motorways.

\section{INTRODUCTION}

Attica Toll way in the Athens Ring Road also called 'Attiki Odos,' is a pioneering project constructed on a concession basis and constitutes one of the biggest co-financed road projects in Europe. It belongs to the first generation of co-financed projects awarded in Greece during the 1990s and essentially paved the way and laid the foundations for the execution of future successful concession contracts in Greece and other European countries. It extends along $65 \mathrm{~km}$ and constitutes the ring road of the greater metropolitan area of Athens, with some 4.5 million inhabitants. It is an urban motorway, with two separate directional carriageways, each consisting of three lanes and an emergency lane (hard shoulder). The suburban railway of Athens greater area was also incorporated in this transportation network and is constructed in the central reservation of the motorway linking some 30 municipalities and serving millions of people every year [1]. The harmonious co-existence of the motorway with the environment and the assurance of a sustainable development of the urban road network, is a difficult task, but nevertheless successfully achieved by Attica Tollway regarding especially environmental noise and air pollution. One of the main axes of this policy lies through the operation of a comprehensive operation management, including environmental monitoring, assessment, and implementation of the appropriate mitigation measures with emphasis on the acoustic and atmospheric environment protection and the sustainable land use organization [2].

Attica Tollway, a closed motorway, with controlled access points, consists of two sections: (a) the Elefsina-Stavros-Spata Motorway (ESSM), extending along approximately $52 \mathrm{~km}$, and (b) the Imittos Western Peripheral Motorway (IWPM-DPLY), extending along approximately $13 \mathrm{~km}$ with the following main technical characteristics: 
Table 1: Traffic data 2008-2012.

\begin{tabular}{ccc}
\hline Year & Total passages (no. of vehicles) & Heavy vehicles (\%) \\
\hline 2008 & 300,993 & 5.08 \\
2009 & 307,300 & 4.46 \\
2010 & 281,329 & 4.29 \\
2011 & 250,491 & 4.08 \\
2012 & 215,644 & 3.92 \\
\hline
\end{tabular}

- A total length of $65.20 \mathrm{~km}$ with $31.3 \mathrm{~km}$ of service roads network and $150 \mathrm{~km}$ of secondary road network.

- 32 Interchanges, 104 Bridges Tunnels, 37 Rail bridges, and 15 pedestrian over-passes.

- $122,000 \mathrm{~m}^{2}$ of services surfaces.

- A Full Environmental Noise and Atmospheric Pollution Monitoring program based on (a) eight fixed stations and (b) a mobile 24 hours monitoring grid for environmental noise monitoring according to the European Directive 2002/49/EC.

- An fully implemented Road Traffic Noise Action Plan implementing a total of more than $90,000 \mathrm{~m}^{2}$ transparent anti-noise barriers.

The relevant road traffic data for both ESSM and IWPM-DPLY are presented in Table 1.

\section{THE ENVIRONMENTAL NOISE AND AIR POLLUTION MONITORING PROGRAM}

The permanent Environmental Road Traffic Noise and Atmospheric Pollution monitoring network of Attiki Odos (Fig. 1) is based on a state-of-the-art monitoring network of eight fixed stations ensuring both real-time noise and air pollution data collection (24/7). All stations are equipped with environmental noise analyzers ensuring the continuous measurement of the following main environmental road traffic noise indices:

- $\mathbf{L}_{\mathbf{1 0}}(\mathbf{1 8} \mathbf{~ h})$ from 06:00 to 24:00 hours and $\mathbf{L}_{\mathbf{A}}$ eq from 08:00 to 20:00 hours, as per the past Greek legislation [3], and

- $\mathbf{L}_{\text {day }}$ (07:00-19:00), $\mathbf{L}_{\text {evening }}$ (19:00-23:00), $\mathbf{L}_{\text {night }}$ (23:00-07:00), and $\mathbf{L}_{\text {den }}$ as per the relevant European Directive 2002/49/EC and the recent updated legislation [4]

Each monitoring station is also equipped with the following air pollutant's monitoring and meteorological equipment, as per station ID [5,6].

The relevant equipment as allocated per station (Fig. 2) is presented as follows:

- $\mathrm{NO}_{x}$ Analyzer Model 42C Thermo Scientific, based on the standard method for the measurement of the concentration of $\mathrm{NO}_{2}$ and $\mathrm{NO}$ by chemiluminescence.

- CO Analyzer Model 48C Thermo Scientific based on the standard method for the measurement of the concentration of $\mathrm{CO}$ by non-dispersive infrared spectroscopy.

- BTX Analyzer EN14662-3 VOC71M PID Environnment SA, based on the standard method for measurement of benzene concentrations. 

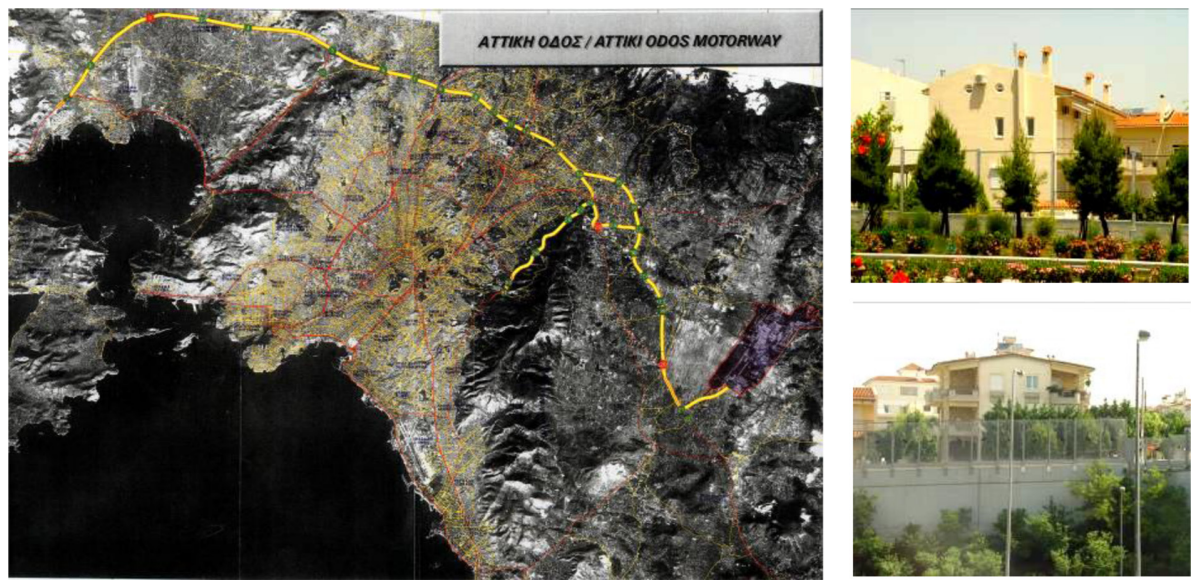

Figure 1: Attiki Odos motorway: a contribution to the urban sustainability and the quality of life.

Table 2: Air pollutant and meteorological equipment per monitoring station.

\begin{tabular}{|c|c|c|c|c|c|c|}
\hline Station ID & $\mathrm{CO}$ & $\begin{array}{l}\mathrm{NO}, \mathrm{NO}_{2} \\
\mathrm{NO}_{x}\end{array}$ & $\begin{array}{c}\mathrm{PM}_{10} \text { and } \\
\mathrm{PM}_{2.5}\end{array}$ & BTEX & $\begin{array}{l}\text { Wind speed } \\
\text { and direction }\end{array}$ & $\begin{array}{l}\text { Temp., rel. humidity } \\
\text { and rain height }\end{array}$ \\
\hline A14 & $\mathrm{x}$ & $\mathrm{X}$ & & & $\mathrm{X}$ & $\mathrm{x}$ \\
\hline A11 & $\mathrm{x}$ & $\mathrm{X}$ & & & $\mathrm{X}$ & $\mathrm{x}$ \\
\hline A10 & $\mathrm{x}$ & $\mathrm{X}$ & & & $\mathrm{X}$ & $\mathrm{x}$ \\
\hline A08.1 & $\mathrm{x}$ & $\mathrm{X}$ & & & $\mathrm{X}$ & $\mathrm{x}$ \\
\hline A08.2 & $\mathrm{x}$ & $\mathrm{X}$ & $\mathrm{x}$ & $\mathrm{x}$ & $\mathrm{X}$ & $\mathrm{x}$ \\
\hline A06 & $\mathrm{x}$ & $\mathrm{X}$ & & & $\mathrm{X}$ & $\mathrm{x}$ \\
\hline IWPM 1-DPLY1 & $\mathrm{x}$ & $\mathrm{X}$ & & & $\mathrm{X}$ & $\mathrm{x}$ \\
\hline IWPM 2-DPLY2 & $\mathrm{x}$ & $\mathrm{X}$ & $\mathrm{x}$ & $\mathrm{x}$ & $\mathrm{X}$ & $\mathrm{x}$ \\
\hline
\end{tabular}
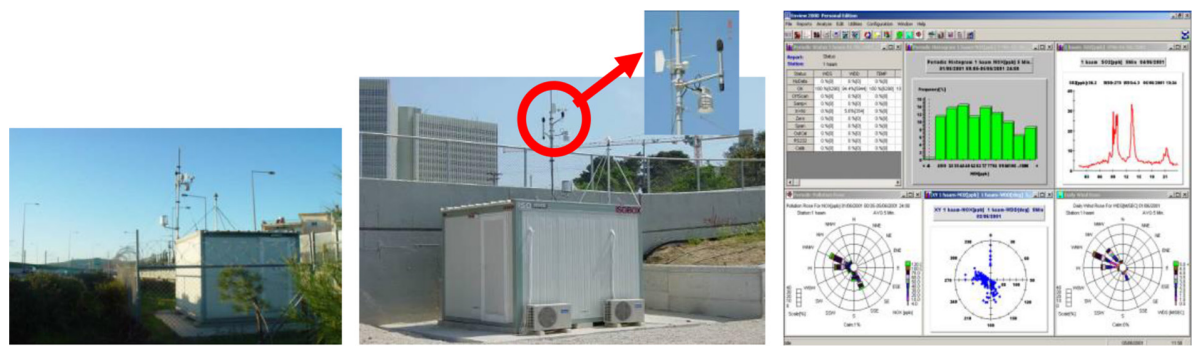

Figure 2: Typical views of A14 and A11 monitoring stations and real-time screens at the control center. 

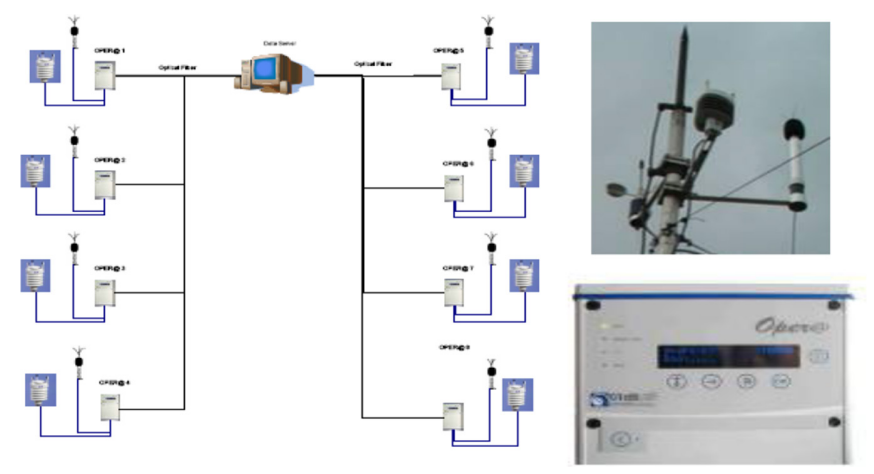

Figure 3: Environmental Noise Monitoring Station network in Attiki Odos.

- $\mathrm{PM}_{10}$ Analyzer EN12341 TEOM 1400a Thermo Scientific, based on the equivalent method for the measurement of the concentration of PM by the tapered element oscillating microbalance method.

- $\mathrm{PM}_{2.5}$ Analyzer EN14907 SHARP 5030 Thermo Scientific, based on the equivalent hybrid method for the measurement of the concentration of particulate by beta attenuation with Carbon 14 and an optical method.

All the above analyzers are installed in a special shelter equipped with a full air conditioning system; electrical panel with surge protection; and full internal wiring, lights, and voltage stabilizer for the instruments. Also sampling manifolds with suction blower, sample ports, filter holders for Teflon filter, and a pneumatic connection of all analyzers with manifold and exhaust are installed. The air pollutants' measurements and diagnostics from the instruments are collected continuously with an industrial-quality PC equipped with the dedicated software EnvidasFW. Each PC is connected to the wide-area fibber optic network of Attiki Odos. The control room, is equipped with a central PC equipped with dedicated software communicating continuously with all stations collecting all data (measurements, diagnostics, digital information) to the central database, generating when necessary on-screen alarms and on-line graphs for the real-time monitoring of the pollution monitoring operators (Fig. 3).

Data are pushed and shared between various operators as Attikes Diadromes S.A. (Athens Ring Road designated operator), Ministry of the Environment, and others, via a dedicated Internet application for pollution monitoring called AIRDMS. There is also minimum 15-day calibration and maintenance service as per the suggestions of the analyzers' manufacturers. Each station is equipped with calibration gasses for these purposes. The environmental noise monitoring equipment is based on independent -per station- noise analyzers OPER@-EX (with full weather and bird protection capabilities for all microphones) connected to the main control center through the fibber optic network. The general layout of the noise monitoring system (at 3.8-4.20 microphone height in full compliance with 2002/49/EU Directive) is presented in Fig. 3.

\section{ENVIRONMENTAL AIR POLLUTION AND NOISE CRITERIA AND LIMITS}

The relevant criteria and limits for all monitored air pollutants are presented in Table 3 [7].

The new maximum values for the relevant European noise indices introduced by the Ministry of the Environment for Strategic Noise Mapping purposes [4] measured at a height of 3.8-4.0 m and within a minimum distance of $2 \mathrm{~m}$ from the closest - to the road noise source - façade are as follows: 
Table 3: Air pollutants criteria and limits.

\begin{tabular}{lll}
\hline Air pollutant & \multicolumn{1}{c}{ Criterion time period } & \multicolumn{1}{c}{ Concentration limit } \\
\hline $\mathrm{NO}_{2}$ & One hour average & $\begin{array}{l}200 \mu \mathrm{gg} / \mathrm{m}^{3} \text {, not to be exceeded more than } 18 \\
\text { times during a calendar year }\end{array}$ \\
$\mathrm{CO}$ & Maximum daily eight hour mean & $10 \mathrm{mg} / \mathrm{m}^{3}$ \\
$\mathrm{PM}_{10}$ & Daily & $50 \mu \mathrm{g} / \mathrm{m}^{3}$, not to be exceeded more than 35 \\
& & times during a calendar year \\
$\mathrm{PM}_{10}$ & Calendar year & $40 \mu \mathrm{g} / \mathrm{m}^{3}$ \\
$\mathrm{PM}_{2.5}$ & Calendar year & $25 \mu \mathrm{g} / \mathrm{m}^{3}$ \\
Benzene & Calendar year & $5 \mu \mathrm{g} / \mathrm{m}^{3}$ \\
\hline
\end{tabular}

- Environmental Noise Index $\mathbf{L}_{\text {den }} \leq 70 \mathrm{~dB}(\mathrm{~A})$ and

- Environmental Noise Index $\mathbf{L}_{\text {night }} \leq 60 \mathrm{~dB}(\mathrm{~A})$, where:

$$
L_{\text {den }}=10 \lg \frac{1}{21}\left(12 * 10 \frac{L_{\text {day }}}{10}+4 * 10 \frac{L_{\text {evening }}+5}{10}+8 * 10 \frac{L_{\text {night }}+10}{10}\right)
$$

\section{ENVIRONMENTAL AIR POLLUTION MONITORING: RESULTS}

The monitoring system was updated in 2009/2010, to its current structure presented above (Fig. 2 and Table 2). Regarding air pollutants monitoring in the following graphs for 2010, 2011, and 2012, the relevant data per pollutant, are presented for all stations, showing compliance with the above limits [7]. The use of fuels [8], mainly in automobiles (but also in industrial boilers or power-generating stations) produces nitrous oxide (NO) along with rather small amounts of nitrogen dioxide $\left(\mathrm{NO}_{2}\right)$. NO through various chemical reactions that are enhanced by the presence of solar radiation is converted to $\mathrm{NO}_{2}$. These two substances $\left(\mathrm{NO}\right.$ and $\left.\mathrm{NO}_{2}\right)$ form the starting materials for a vast array of chemical reactions that lead to photochemical oxidants $\left(\mathrm{O}_{3}, \mathrm{NO}_{2}, \mathrm{PAN}\right)$, which under certain atmospheric conditions participate in the creation of Photochemical Smog. To fully appreciate photochemical smog formation, one must first recognize that nitrogen is transformed between many different substances in the atmosphere. Automobile exhausts release NO along with small amounts of $\mathrm{NO}_{2}$. In Fig. 4, a diagram is presented, showing the changes in atmospheric concentrations for nitrogen oxide, $\mathrm{NO}_{2}$, non-methane hydrocarbons, aldehydes, and oxidants [9].

For the first semester of 2011, only one exceedance was observed at A11 station. Some limited exceedance was observed at A06 station and only one at A08.1 station, but within the regulated limit.

For CO air pollutant, however, no exceedance was observed throughout the 2010, 2011, and 2012 period as per the following figures.

$\mathrm{PM}_{10}$ exceeds the limits at station A08.2, due to its location, practically in the edge of the road. $\mathrm{PM}_{10}$ on an annual basis exceeds the $40 \mu \mathrm{g} / \mathrm{m}^{3}$ limit in 2010 in both stations where the equipment is installed and in the first semester of 2011 at the A08.2 station. $\mathrm{PM}_{2.5}$ is on the limit in both years for A08.2 but below limit at IWPM2 (DPLY2) station.

Regarding benzene (BTEX), no exceedance is observed throughout the 2010-2012 period in the above-monitoring stations A08.2 \& IWPM2 (DPLY2) as presented in the figure hereafter.

In conclusion, at 'Attiki Odos' Ring Road network, some exceedance in dust in the $\mathrm{PM}_{10}$ fraction were monitored with emphasis on the closest - to road edge - A082 station (Figs 5-15). 


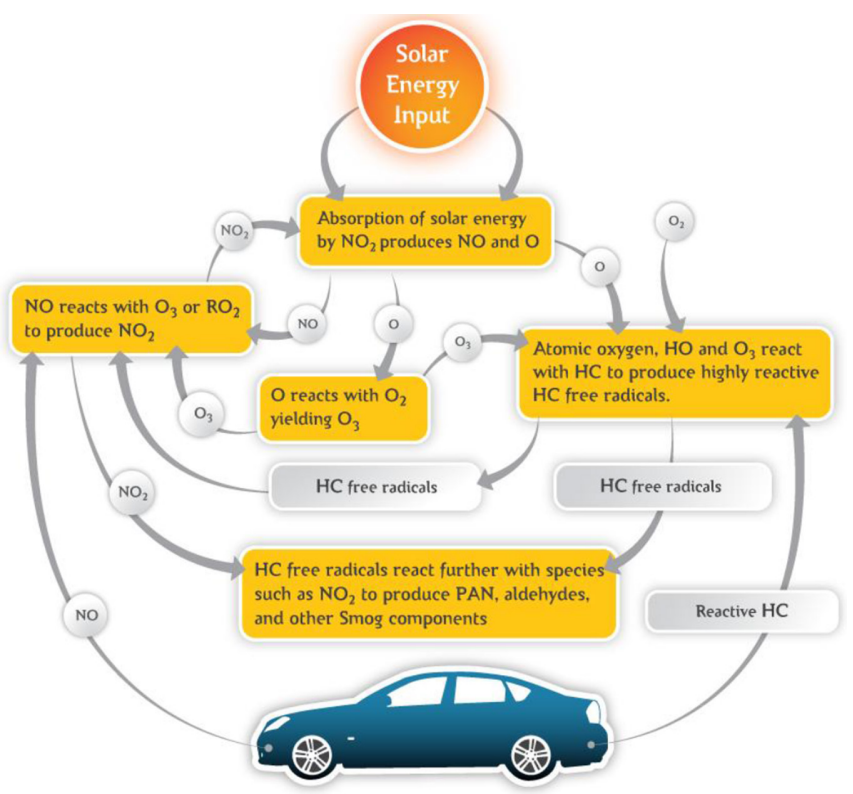

Figure 4: Formation of the photochemical smog - daily chemical transformations.

NO2 - 1Hour Avg - 2010

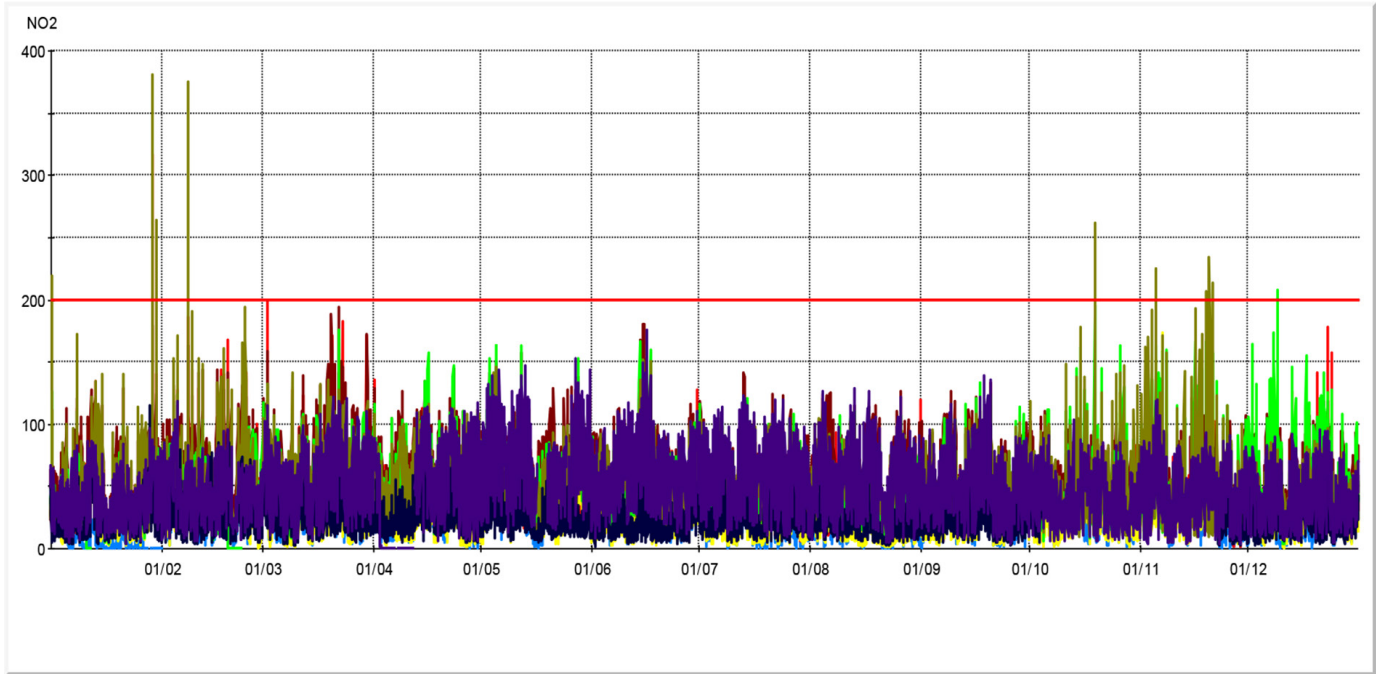

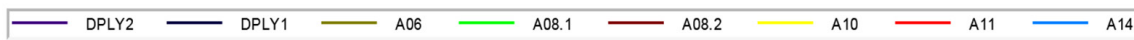

Figure 5: Nitrogen dioxide, 2010: $1 \mathrm{~h}$ avg $\left(\mu \mathrm{g} / \mathrm{m}^{3}\right)$. 
NO2 - 1Hour Avg - 2011
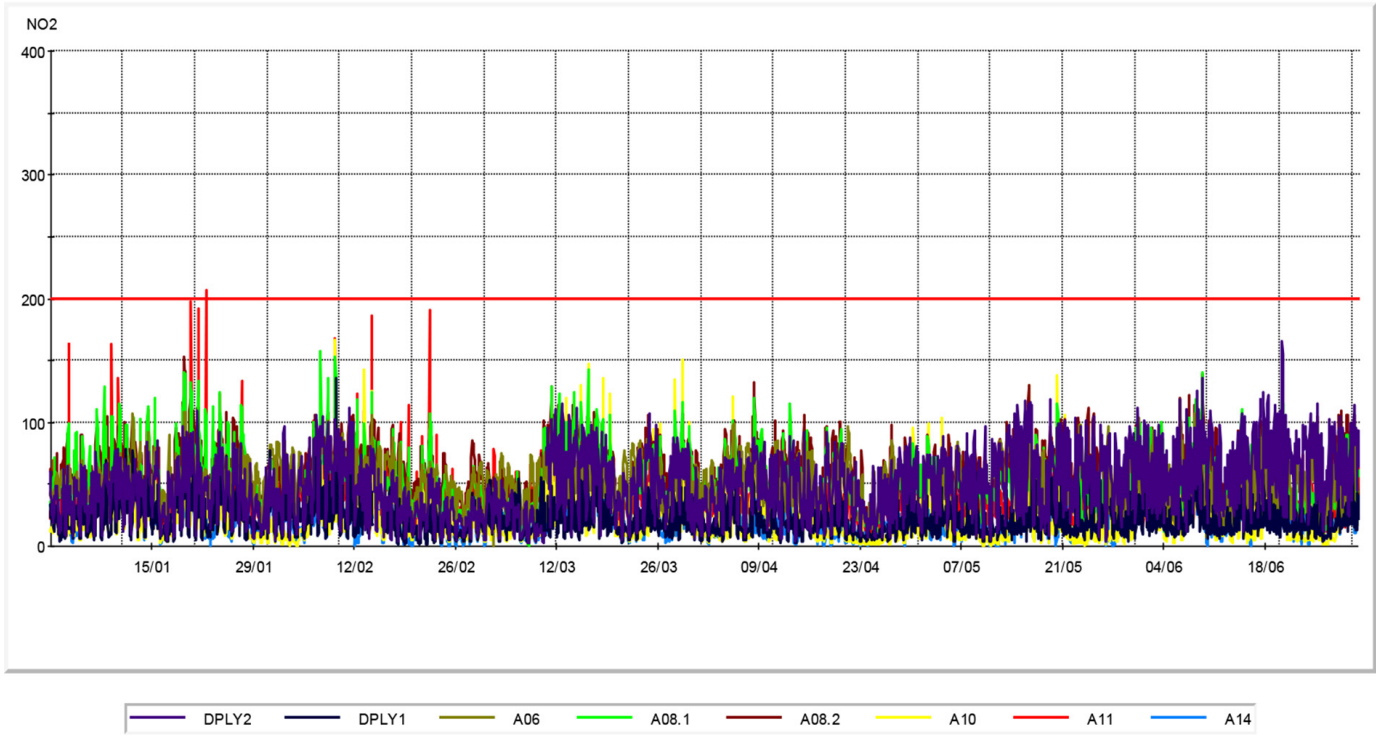

Figure 6: Nitrogen dioxide, 2011: $1 \mathrm{~h}$ avg $\left(\mu \mathrm{g} / \mathrm{m}^{3}\right)$.

NO2 1 Hour Avg - 2012
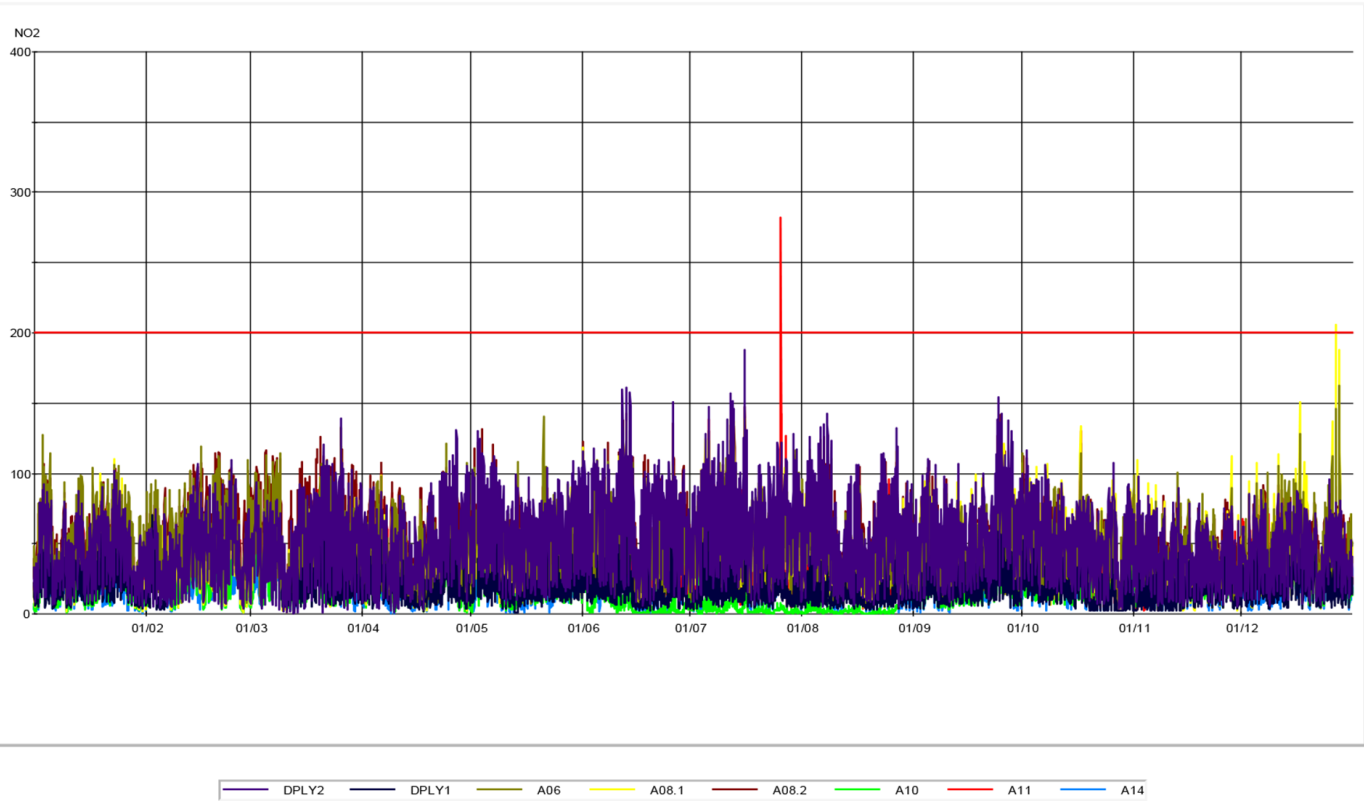

Figure 7: Nitrogen dioxide, 2012: $1 \mathrm{~h}$ avg $\left(\mu \mathrm{g} / \mathrm{m}^{3}\right)$. 


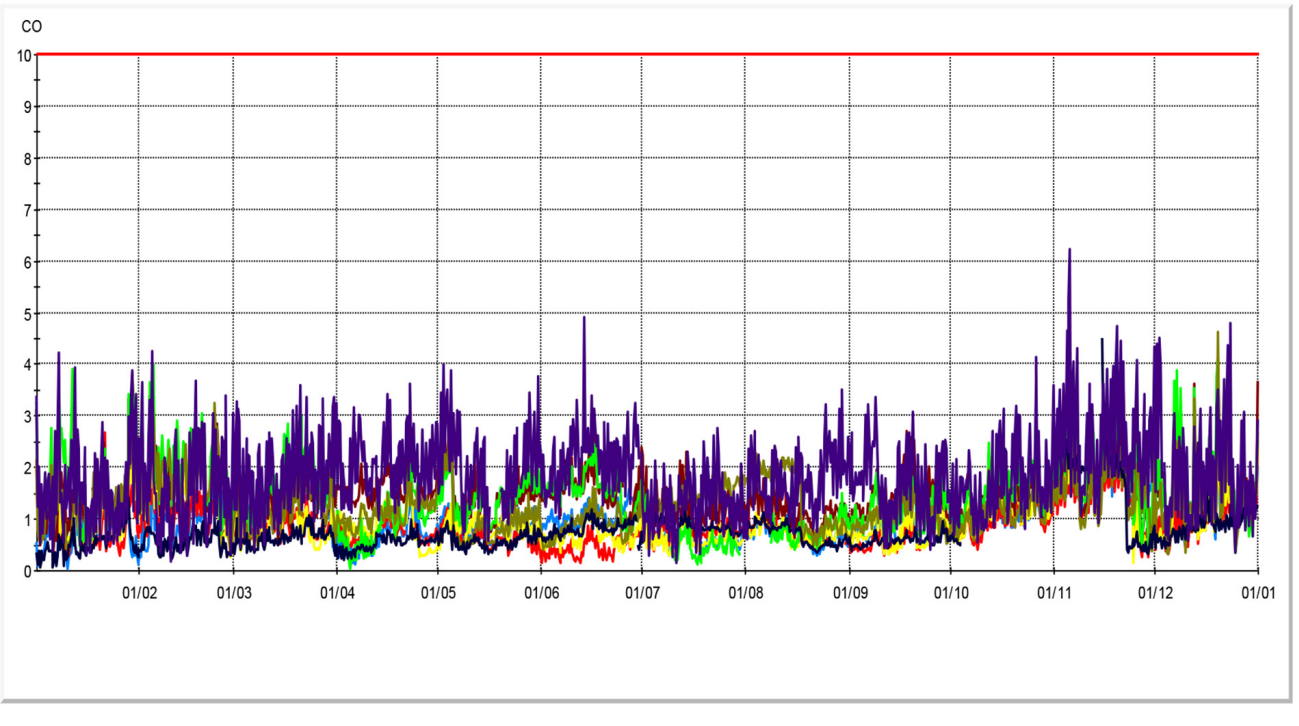

Figure 8: Carbon monoxide, 2010: $8 \mathrm{~h} \max$ average $\left(\mathrm{mg} / \mathrm{m}^{3}\right)$.

CO - 8Hour Avg - 2011

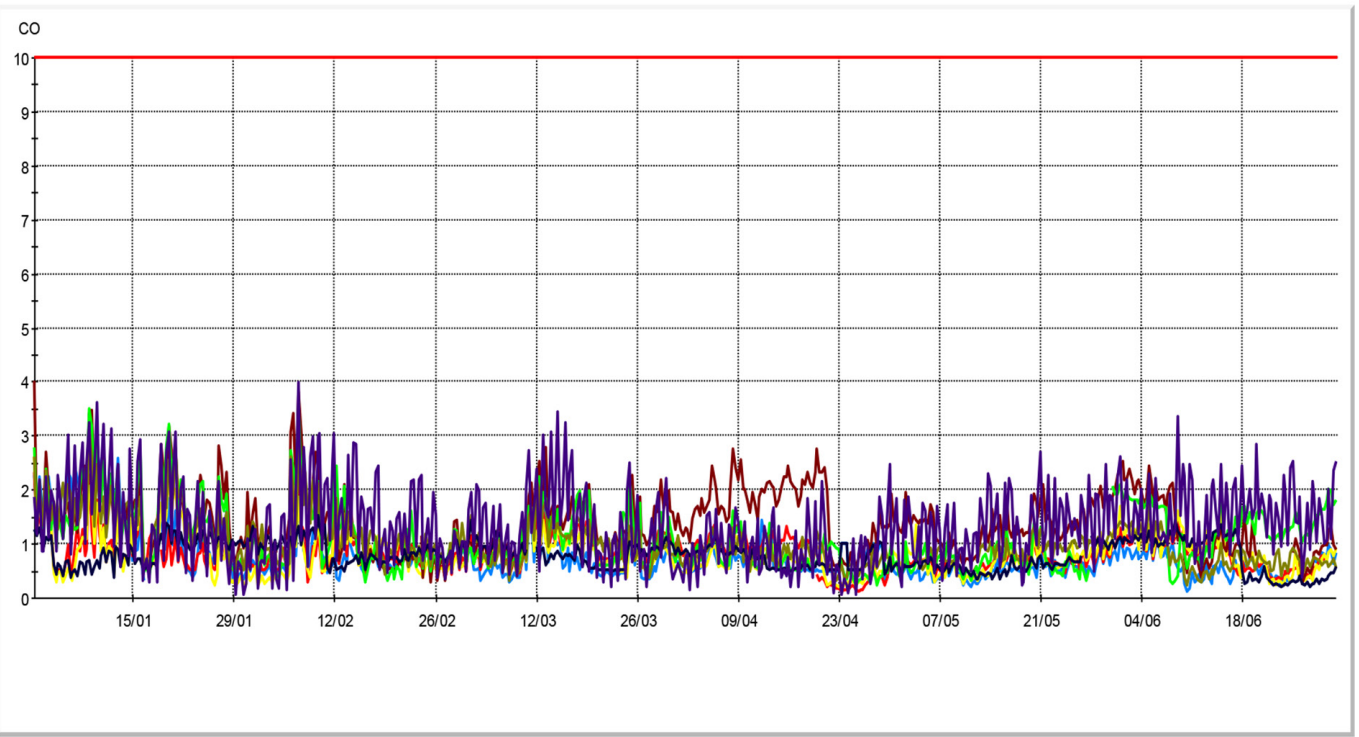

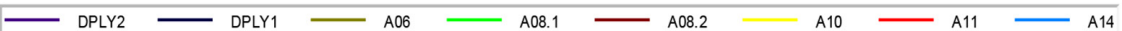

Figure 9: Carbon monoxide, 2011: $8 \mathrm{~h}$ max average $\left(\mathrm{mg} / \mathrm{m}^{3}\right)$. 

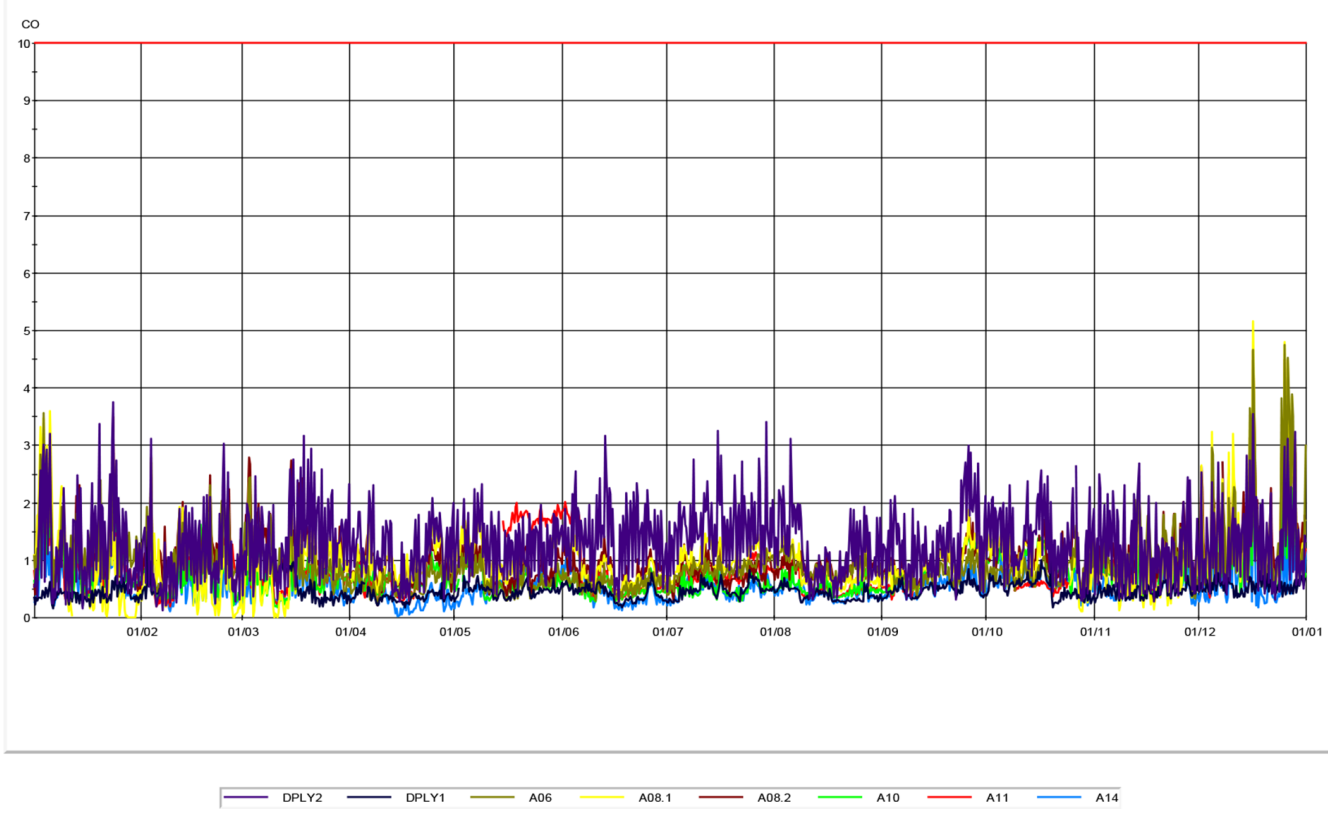

Figure 10: Carbon monoxide, 2012: $8 \mathrm{~h}$ max average $\left(\mathrm{mg} / \mathrm{m}^{3}\right)$.

PM 10 - 24Hour Avg - 2010

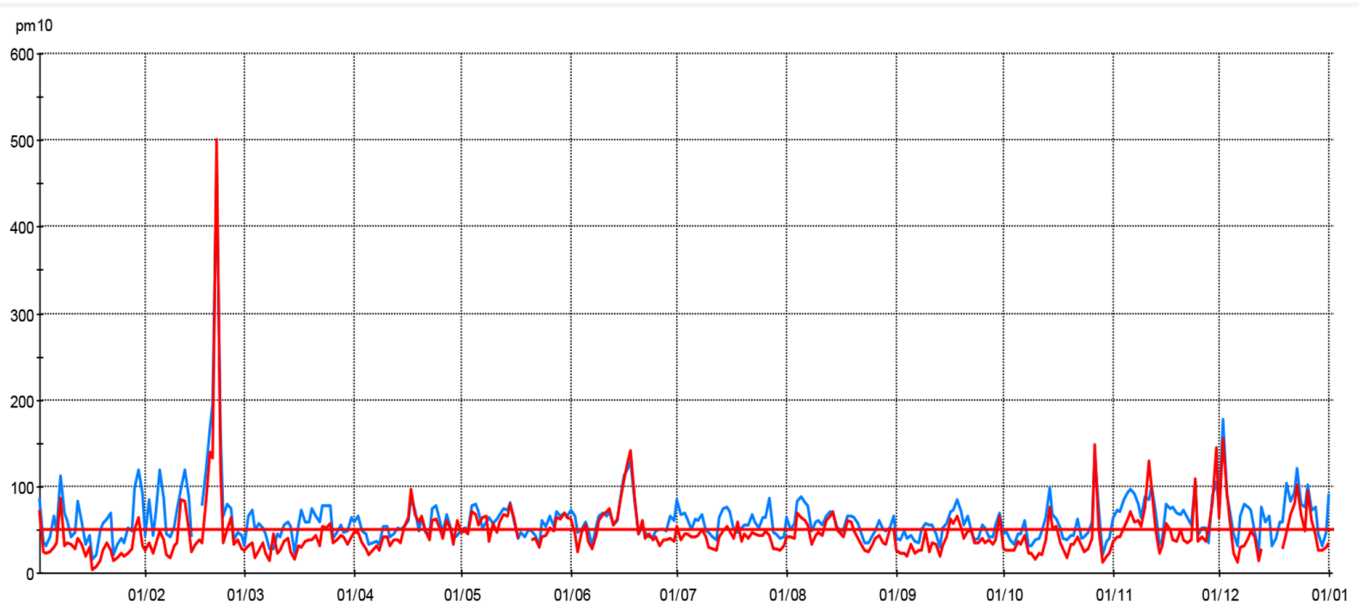

$\longrightarrow$ DPLY2 $\longrightarrow$ A08.2

Figure 11: $\mathrm{PM}_{10}$ daily $\left(\mu \mathrm{g} / \mathrm{m}^{3}\right), 2010$. 
PM10 - 24Hour Avg - 2011

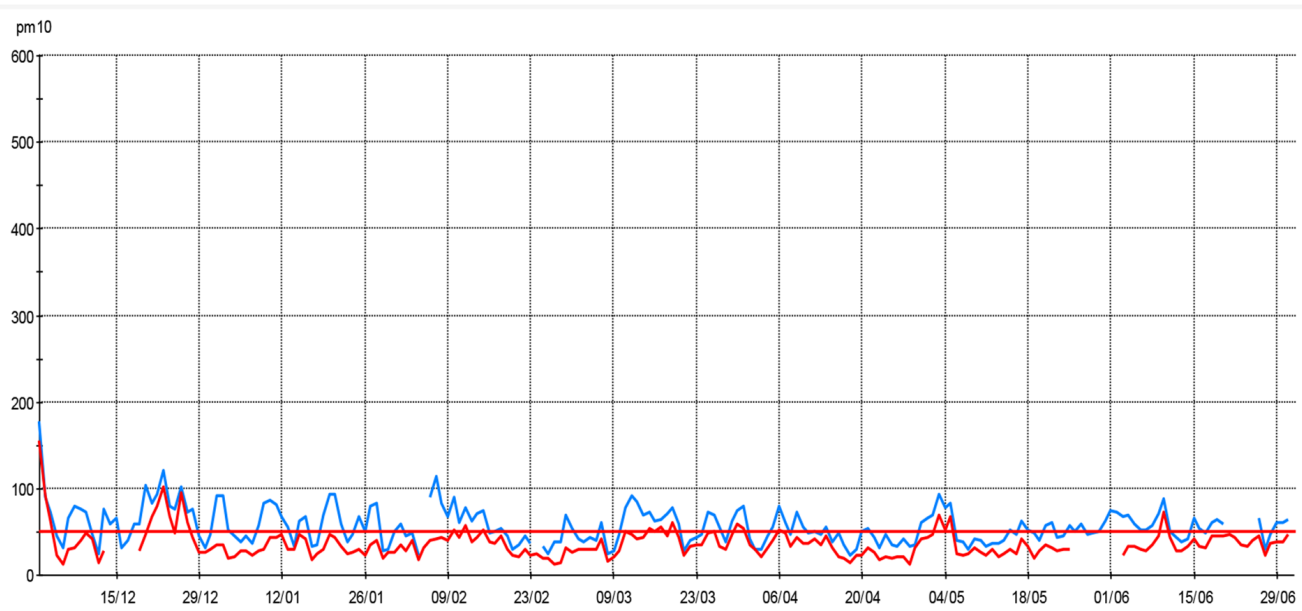

$$
\text { — DPLY2 }-{ }_{A 08.2}
$$

Figure 12: $\mathrm{PM}_{10}$ daily $\left(\mu \mathrm{g} / \mathrm{m}^{3}\right), 2011$.

PM10 24 Hour Avg - 2012

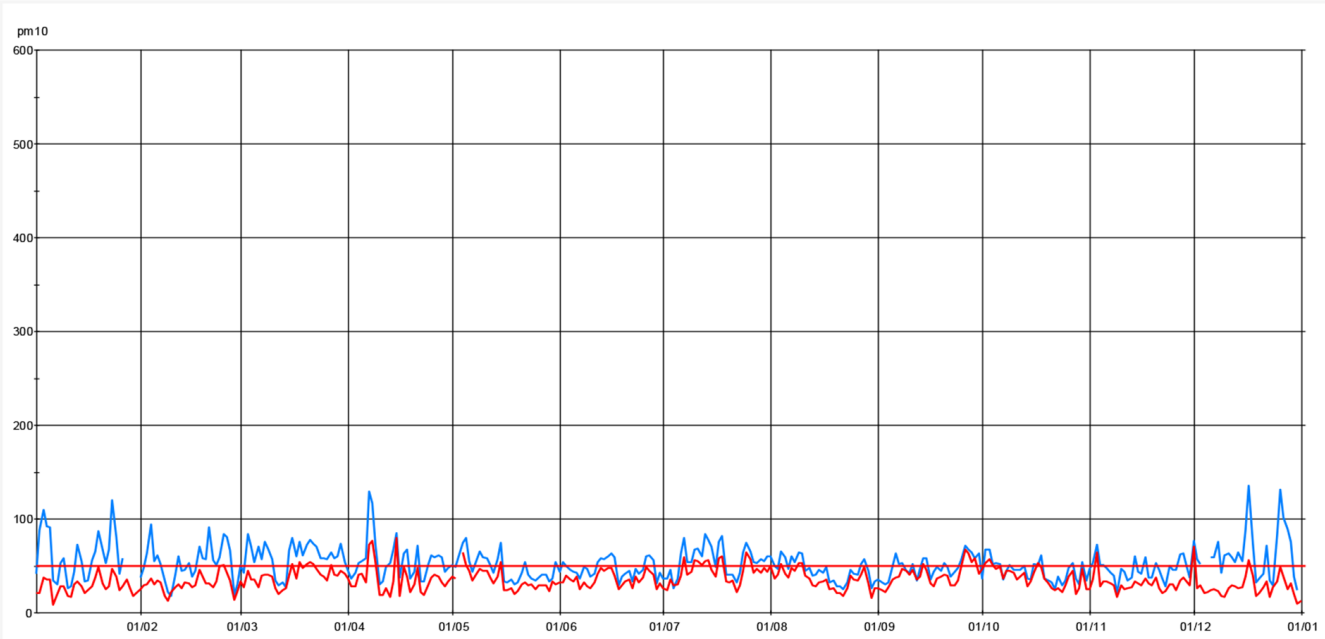

${ }_{\text {DPLY2 }}{ }^{\mathrm{AOB} .}$

Figure 13: $\mathrm{PM}_{10}$ daily $\left(\mu \mathrm{g} / \mathrm{m}^{3}\right), 2012$. 


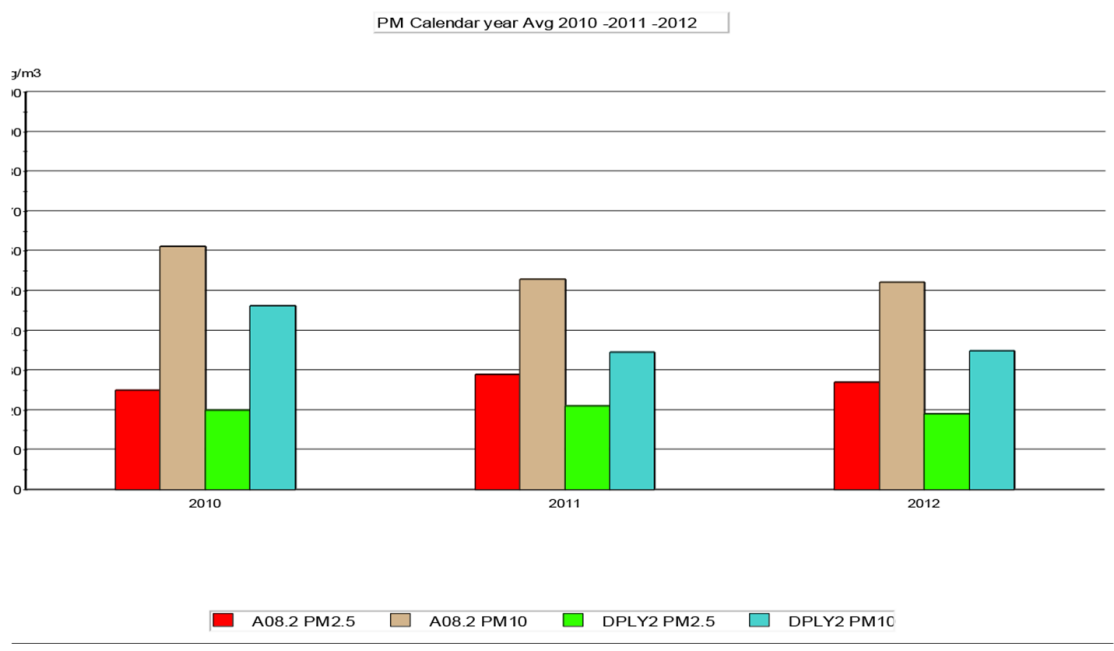

Figure 14: Annual Dust Comparison ( $\mu \mathrm{g} / \mathrm{m} 3)$ at A08.2 and IWPM2 (DPLY2).

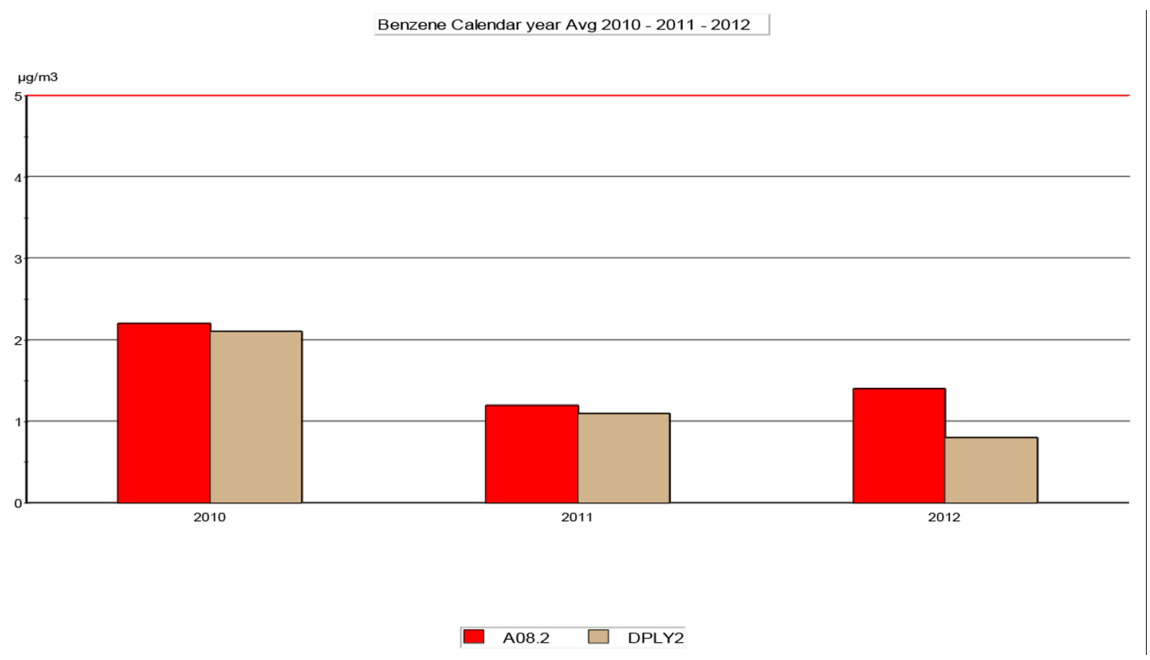

Figure 15: Annual Benzene Comparison $\left(\mu \mathrm{g} / \mathrm{m}^{3}\right)$ at A08.2 and IWPM2 (DPLY2).

\section{ENVIRONMENTAL NOISE MONITORING: RESULTS}

The Environmental Noise Monitoring system is equipped with a continuous real-time weather data recording for all stations and is fully in compliance with both the newest Greek legislation and European Directive indices. A relevant Certificate of Conformance is issued every two years in order to control the measurement setup, to identify correctly and to provide both high quantity and quality levels of monitoring. The environmental noise monitoring indices fluctuation is presented in the following graphs (monthly average data for 2010, 2011, and 2012) for all stations (note: some graph gaps are due to the calibration and maintenance periods) (Figs. 16 and 17). 
Environmental Noise Index Lden :1/1/2010-31/12/2012

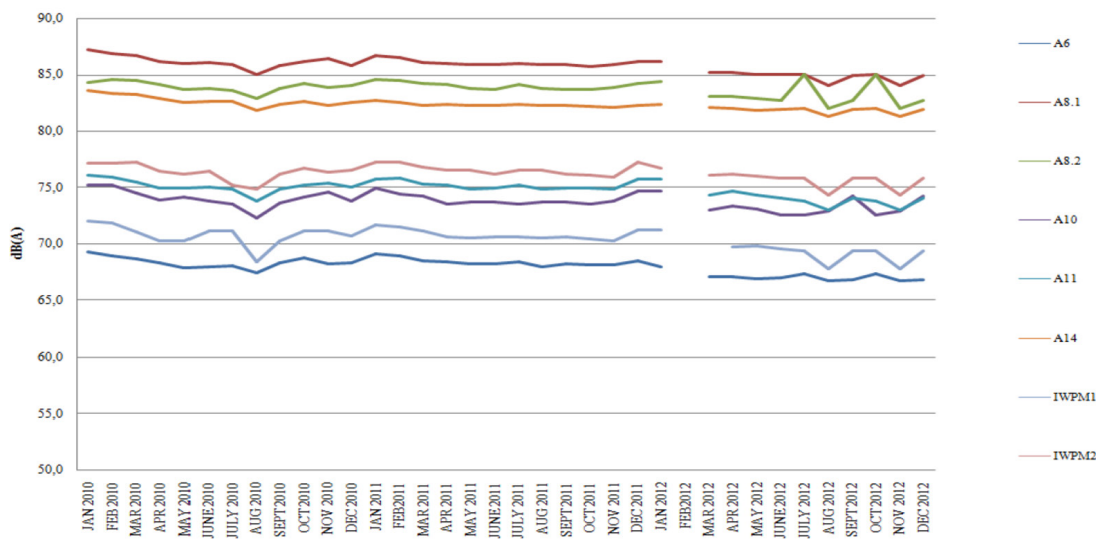

Figure 16: Environmental noise index $\mathbf{L}_{\mathrm{den}}$.

Environmental Noise Index Lnight :1/1/2010-31/12/2012

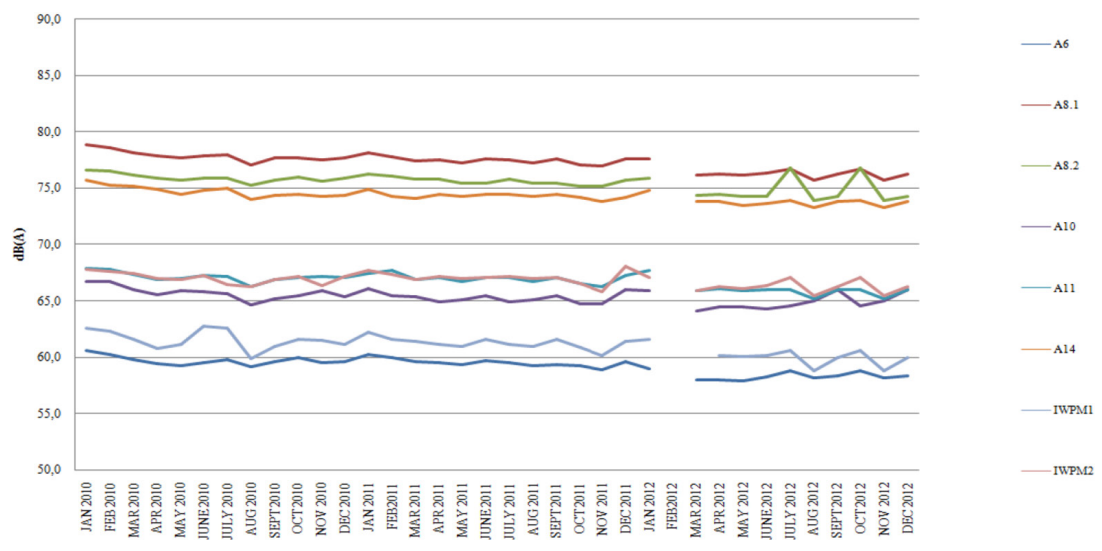

Figure 17: Environmental noise index $\mathbf{L}_{\text {night }}$.

\section{ROAD TRAFFIC FLOWS AND SOME COMPARATIVE MONITORING DATA}

Regarding the relevant traffic flow data for the above monitoring period the monthly average day traffic flow for all locations is presented in the figure hereafter (Fig. 18). The lowest volumes were obviously reported for August, which represent the traditional vacation period with an important part of the population leaving Athens greater area. Especially for both stations (A08.2 and IWPM2-DPLY2) here a full equipment version were installed including PM10-PM2.5 and BTEX sensors, it is interesting to compare the relevant fluctuation of all air pollutants (all in $\mu \mathrm{g} / \mathrm{m}^{3}$ except $\mathrm{CO}$ in $\mathrm{mg} / \mathrm{m}^{3}$ ) for the given time period (Figs. 19 and 20). Environmental noise fluctuations for all indices are also presented hereafter for comparative purposes. The Road traffic flows daily and monthly average fluctuation and Monthly average noise indices fluctuation for both stations are also presented in Fig. 21 and 22.

The comparative average traffic flow fluctuation is also presented in Fig. 21. 


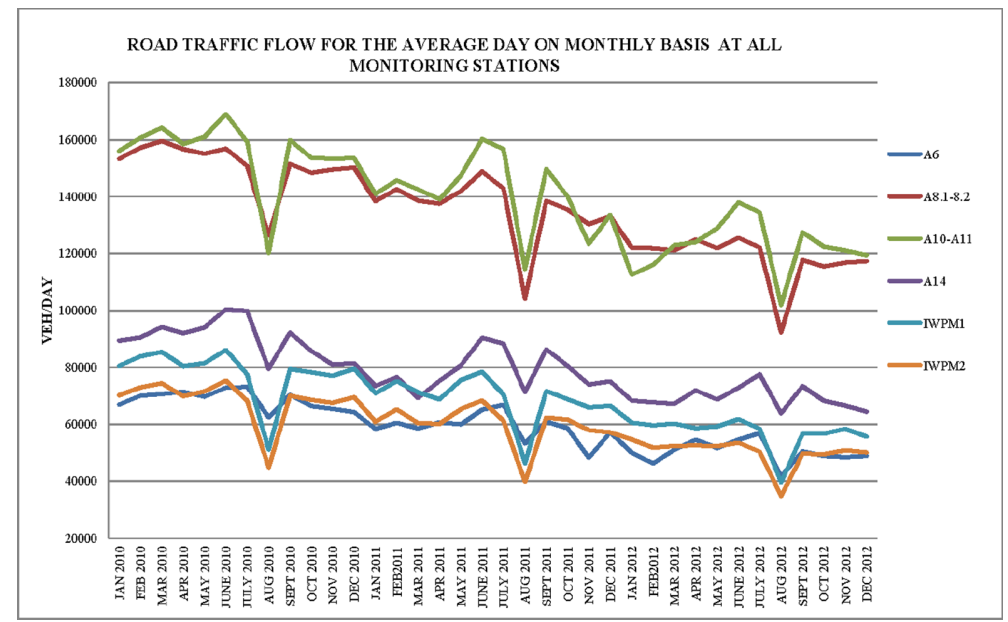

Figure 18: Road traffic flows average day per month for 2010, 2011, and 2012.

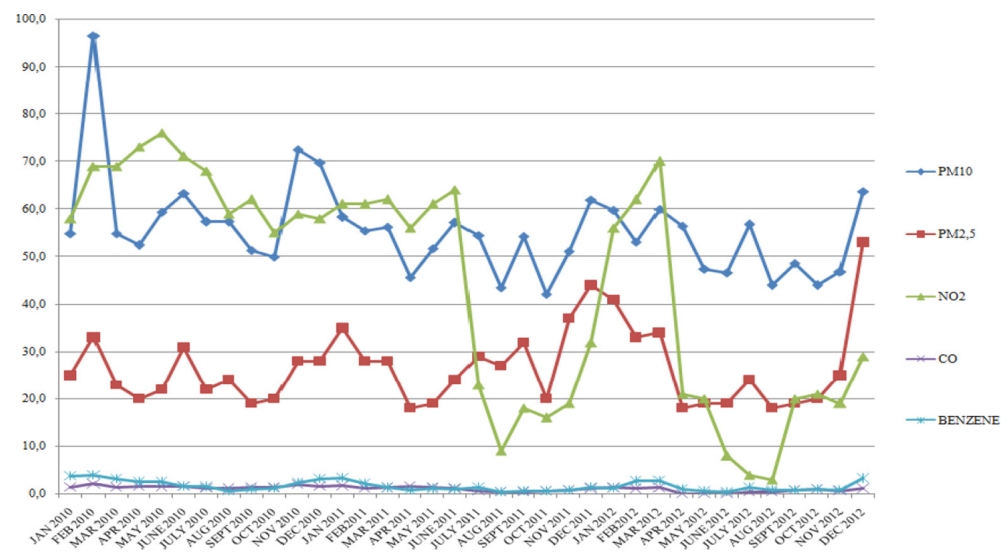

Figure 19: Station A08.2 - all air pollutants.

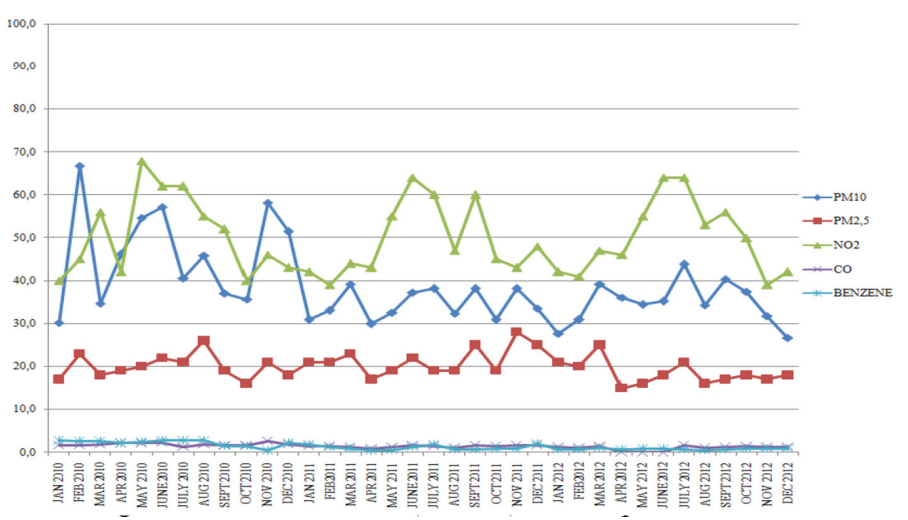

Figure 20: Station IWPM2 (DPLY2) - all air pollutants. 


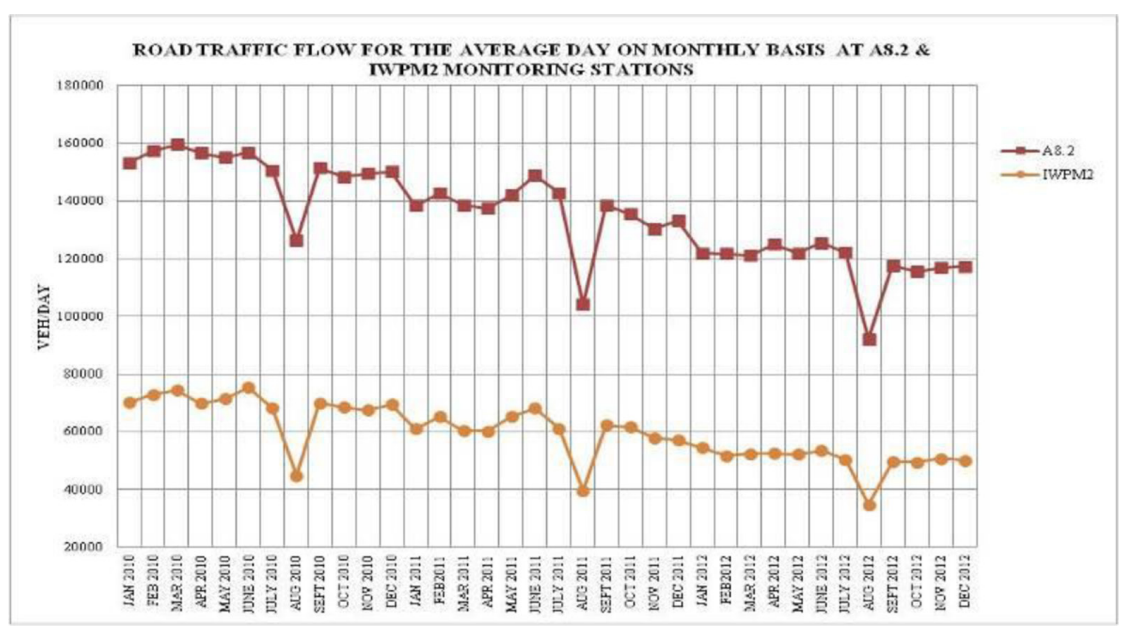

Figure 21: Road traffic flows daily and monthly average fluctuation at both stations.

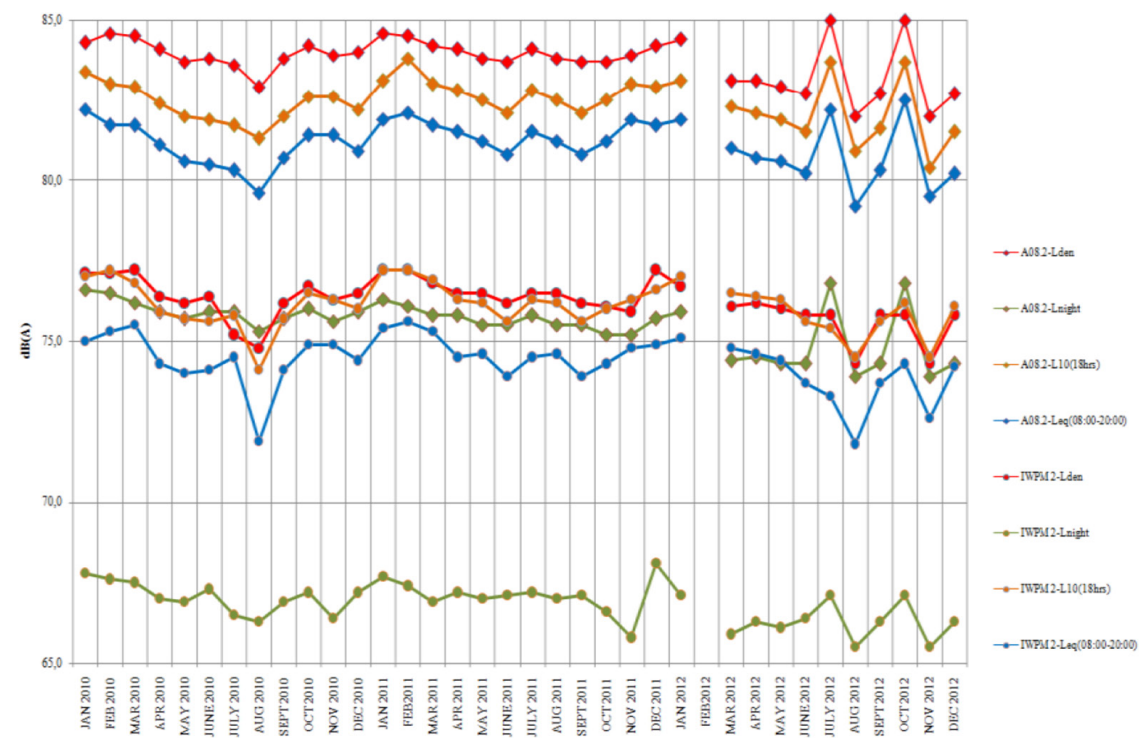

Figure 22: Monthly average noise indices fluctuation at both stations.

Relevant noise indices data presented in figure hereafter are also consistent with traffic flow variations introducing low values for all indices during vacation periods.

\section{CONCLUSIONS AND DISCUSSION}

The construction of Attica Tollway has significantly helped to reduce the traffic congestion in the capital. The motorway has absorbed a significant part of the total daily traffic of vehicles in the Athens Greater area consisting the Greece Mega Urban region, because it offers easier access to remote urban areas of the Attika peninsula, with some 55\% of the motorway's users gaining 
between 16 and 30 minutes of their travel time. according to the relevant data for the period 2007-2009 [1]. As per environmental noise and air pollutants emissions and concentrations, the operation of the motorway in the last three years, has proved to be mainly within the given acceptable criteria for all indices as per the relevant European Directives. Both air pollution and environmental noise monitoring networks in Attiki Odos, are important parameters in order to achieve sustainability of the peri-urban road networks consisting an important tool to evaluate the quality of the environment and the implementation of appropriate mitigation measures. The often unplanned and extensive use of space - especially in overdeveloped urban regions - in order to accommodate more activities will eventually degrade the urban atmospheric and acoustic environment. Excessive road transportation activities is generally expected to introduce severe damage to the urban environment, for the major greater urban areas in Europe, such as Athens metropolitan area, and therefore the necessity for immediate introduction of atmospheric and acoustic environmental indicators, based on a comprehensive and state-of-the-art monitoring networks, is mandatory.

Environmental monitoring networks - as per the presented Attiki Odos system - aim also in the determination and implementation of the necessary environmental mitigation measures regarding both technical interventions and operation measures. However, it is imperative to [10];

- identify of both priorities (e.g. identification of all important urban areas needing relevant action plans) and also the 'best' environmental action plans,

- involve the general public in the procedure to enhance environment quality in the relevant areas

- reflect future developments, e.g. local effects of community measures such as source-oriented noise policy.

Particularly in Attiki Odos motorway, in order to ensure a sustainable development and operation of the motorway, a recent extended Noise Action Plan based on the implementation of an important anti-noise mitigation measures program as part of the relevant Noise Action Plan (NAP 2010) [5] introducing more than $90,000 \mathrm{~m}^{2}$ of transparent noise barriers poly-methyl-methacrylate in some 138 different locations along the road network ensuring both esthetic integration to the urban landscape and bird protection minimizing as well the effect of 'visual intrusion'. Additional mitigation measures introducing partial covering in two major sections of the motorway are already under consideration expecting to enhance the rehabilitation of the acoustic environment. Moreover, financial investments by the urban area authorities are therefore needed to introduce similar monitoring initiatives, and this trend should be further developed. However, other than urban landscapes in the mega-cities ensuring sustainability, there is a need to better understand not only the benefits but also the costs of an uncontrolled development and its effects to atmospheric and acoustic environment [10].

Furthermore and especially regarding the protection of the atmospheric environment, according to the results of the above monitoring program, it is clear that a successful environment protection is not only a matter of the transportation infrastructures. Each individual, in the driver's seat, can contribute to the sustainability of the road network by driving in an environmentally friendly way. The 'Ecological driving' (i.e. 'economical driving') project is running already in Attica Tollway in cooperation with the National Energy Centre, the Centre for Renewable Energy Sources (CRES), promoting eco-driving with a view to protection of the environment. The reduction of fuel consumption as a result of the 'eco-driving' means, reduction of air pollution, i.e. environmental benefit and fuel cost reduction, i.e. economy and savings for the driver. Eco-driving helps the reduction of noise pollution, the minimization of accident rate, and the enhancement of road safety, as well as saving travel time compared with the usual driving mode. As an important component of 
sustainable mobility, it involves smarter and more fuel-efficient driving, representing a new driving culture introducing a best use of the advanced vehicle technologies, while improving road safety and minimizing air pollutants' emissions. Furthermore, in order to achieve a better quality of life in relation to the atmospheric and the acoustic environment in great urban centers it is necessary to introduce appropriate criteria regarding air quality, sleep quality, and disturbance. A continuous upgraded comprehensive legal framework - in conjunction with extensive monitoring networks - is also required enabling a close relation of sustainability development and economic growth and technology [11].

\section{REFERENCES}

[1] http://en.aodos.gr/summary.asp?catid=21597

[2] Eliou, N. \& Vogiatzis, K., Road traffic noise monitoring program \& mitigation measures at the Athens ring motorway, 16th International Congress on Sound and Vibration ICSV 16, Krakow, Poland, 5-9 July 2009.

[3] MD 17252, Criteria \& noise max levels for road networks in Greece, 19 June 1992.

[4] MD 211773/2012 (ФEK 1367/B/27-4-2012), Criteria \& noise max levels for the indices according to the Directive 2002/49/EC of the European parliament and of the council of 25 June 2002 relating to the assessment and management of environmental noise, 2002.

[5] Vogiatzis, K. - TT \& E S.A., Environmental noise study of Attiki Odos: strategic noise maps $\&$ noise action plans, 2010.

[6] Vogiatzis, K.E., Strategic environmental noise mapping \& action plans in Athens ring road (Atiiki Odos) - Greece. WSEAS Transactions on Environment and Development, 7(10), 2011, ISSN 1790-5079. doi: http://dx.doi.org/10.1016/j.jtrangeo.2009.09.003

[7] Directive 2008/50/EC of the European parliament and of the council of 21 May 2008 on ambient air quality and cleaner air for Europe, 2008.

[8] http://mtweb.mtsu.edu/nchong/Smog-Atm1.htm (Original page created by Prof. Dr.Richard Foust, Northern Arizona University).

[9] Greek Ministry of the Environment - Annual Report 2012 (Main atmospheric pollutants), available at http://www.ypeka.gr/LinkClick.aspx?fileticket=xYIP1FO6rIg\%3d\&tabid=490\&langu age=el-GR, May 2013.

[10] Vogiatzis, C., Chaikali, S. \& Chatzopoulou, A., Existing legal framework for environmental acoustics in Greece. 12th International Congress on Sound and Vibration, Lisbon, Portugal, 11-14 July 2005.

[11] Vogiatzis, K.E. \& Psychas, K., Legal aspects on environmental noise and urban soundscape rehabilitation in Mediterranean countries: the case of Greece. Int. Journal of Sustainable Development \& Planning, 7(4), 2012. doi: http://dx.doi.org/10.2495/sdp-v7-n4-484-494 